\title{
Analisa Perbandingan Penggunaan Bahan Bakar Solar Dengan Biodiesel B10 Terhadap Performansi Engine Cummins QSK 45 C
}

\author{
Ardhita Hendriarto ${ }^{1}$, Puji Saksono ${ }^{2}$, Gunawan ${ }^{3}$ \\ ${ }^{1,2,3)}$ Program Studi Teknik Mesin Fakultas Teknologi Industri Universitas Balikpapan \\ Jl. Pupuk Raya Balikpapan. Telp./Fax. 0542-764205 \\ Email : ardhita2826@gmail.com; saksono_puji@yahoo.co.id; gun.salsa@gmail.com
}

\begin{abstract}
The type of diesel fuel comes from the petroleum, which its existence is the more long and more less, so that biodiesel represents the alternative solution as the place of it. Biodiesel B10 is the type of fuel for the diesel engine by the composition of $10 \%$ biodiesel and $90 \%$ of diesel fuel. This research is conducted to analyse comparison of usage of diesel fuel with B10 biodiesel to the value of performance of engine Cummins QSK 45 C. This equipment used for the test of performance is Taylor DS4010 dynamometer. Result of examination using biodiesel B10 got by this maximal power value equal to 1432.28 HP $(97.51 \%)$ compared to diesel fuel equal $1468.763 \mathrm{HP}$, at rotation of engine $1901 \mathrm{rpm}$. While the value of torque maximal equal $4929.3 \mathrm{lb}-\mathrm{ft}(98.27 \%)$ compared to diesel fuel equal 5016.189 at rotation of engine $1301 \mathrm{rpm}$.
\end{abstract}

Key words: The type of fuel, Dynotest, engine performance

\begin{abstract}
Abstrak
Bahan bakar jenis solar berasal dari minyak bumi yang keberadaannya semakin lama semakin menipis, sehingga biodiesel merupakan solusi alternatif sebagai penggantinya. Biodiesel B10 merupakan jenis bahan bakar untuk mesin diesel dengan komposisi 10 \% biodiesel dan $90 \%$ solar. Penelitian ini dilakukan untuk menganalisa perbandingan penggunaan bahan bakar solar dengan biodiesel B10 terhadap nilai performansi engine Cummins QSK 45 C. Peralatan yang digunakan untuk uji performansi yaitu dynamometer Taylor DS4010. Hasil pengujian dengan menggunakan biodiesel B10 didapatkan nilai daya maksimal sebesar 1432,28 HP (97,51 \%) dibandingkan solar sebesar 1468,763 HP, pada putaran engine 1901 rpm. Sedangkan nilai torsi maksimal sebesar 4929,3 lb-ft (98,27 \%) dibandingkan solar sebesar 5016,189 pada putaran engine $1301 \mathrm{rpm}$.
\end{abstract}

Kata kunci : Jenis Bahan Bakar, Dynotest, Performansi Engine

\section{Pendahuluan}

Biodiesel merupakan jenis bahan bakar alternatif yang dapat diperbaharui dan ramah lingkungan. Bahan bakar ini terbuat dari minyak nabati yang kemudian diubah menjadi campuran bahan bakar pada minyak solar.

Tingkat aktifitas kegiatan di sektor pertambangan yang semakin tinggi dan jumlah unit alat berat yang semakin banyak, tentu saja penggunaan bahan bakar fosil jenis solar ini sangatlah dibatasi. Dengan adanya program pemerintah akan penghematan terhadap pemakaian bahan bakar fosil jenis solar akan diganti dengan menggunakan biodiesel B10.
Adapun rumusan masalah pada penelitian ini adalah bagaimana perbandingan penggunaan bahan bakar jenis solar ke biodiesel B10 terhadap performansi engine Cummins QSK 45 C ?

Tujuan peneltian yaitu agar dapat memahami dan menganalisa persentase perubahan performansi engine saat menggunakan bahan bakar jenis solar dengan biodiesel B10.

\section{Tinjauan Pustaka}

2.1. Keunggulan Biodiesel Dari
Tanaman Jarak Dibandingkan
Solar


Dibandingkan dengan minyak solar, biodiesel B10 memiliki angka memiliki angka cetane yang berbeda. Biodiesel B10 memiliki angka cetane 49,2 sedangkan solar 49 Angka cetane (cetane rating) adalah tolak ukur kemudahan menyala atau terbakar dari suatu bahan bakar di dalam mesin diesel. Semakin tinggi angka cetane semakin aman nilai emisi gas buangnya karena bahan bakar dapat terbakar dengan sempurna sehingga kadar emisi gas sulfur (Sox), nitrogen (Nox) dan karbon yang termasuk dalam gas-gas rumah kaca lebih rendah. Selain itu dalam membangkitkan tenaga listrik, biodiesel tidak memerlukan genset baru karena minyak jarak dapat langsung digunakan pada genset yang sudah ada.

Tabel 1. Perbandingan Typical

Characteristic Solar Dan Biodiesel 10

\begin{tabular}{|c|l|c|c|}
\hline No & \multicolumn{1}{|c|}{ Karekteristik } & Solar & $\begin{array}{c}\text { Biodiesel } \\
\mathrm{B} 10\end{array}$ \\
\hline 1. & Angka Setana & 49 & 49,2 \\
\hline 2. & $\begin{array}{l}\text { Berat Jenis Pada } \\
15^{\circ} \mathrm{C}(\mathrm{kg} / \mathrm{m} 3)\end{array}$ & 8442 & 8463 \\
\hline 3. & $\begin{array}{l}\text { Viskositas Pada } \\
40^{\circ} \mathrm{C}(\mathrm{mm} 2 / \mathrm{s})\end{array}$ & 3,5 & 3,604 \\
\hline 4. & Titik Nyala $\left({ }^{\circ} \mathrm{C}\right)$ & 60 & 62,2 \\
\hline 5. & $\begin{array}{l}\text { Karbon Residu } \\
\text { (\%massa) }\end{array}$ & $<0,1$ & 0,02 \\
\hline 6. & $\begin{array}{l}\text { Kandungan Air } \\
\text { (mg/kg) }\end{array}$ & 76 & 177 \\
\hline
\end{tabular}

Tabel 2. Laboratory Analysis

\begin{tabular}{|l|c|c|c|c|}
\hline Parameters & Result & Units & $\begin{array}{c}\text { ASTM } \\
\text { D7467 } \\
\text { Standard } \\
\text { Specificatio } \\
\mathrm{n}\end{array}$ & Method \\
\hline \hline Acid Value & 0.0616 & $\begin{array}{c}\mathrm{mgK} \\
\mathrm{OH} / \mathrm{g}\end{array}$ & $\max 0.3$ & $\begin{array}{c}\text { AOCS } \\
\text { Cd 3d-63 }\end{array}$ \\
\hline $\begin{array}{l}\text { Water } \\
\text { Content }\end{array}$ & 79.22 & $\mathrm{ppm}$ & $\max 500$ & $\begin{array}{c}\text { EN ISO } \\
12937\end{array}$ \\
\hline $\begin{array}{l}\text { Oxidation } \\
\text { Stability }\end{array}$ & $>24$ & Hours & $\min 6$ & $\begin{array}{c}\text { En } \\
1412\end{array}$ \\
\hline $\begin{array}{l}\text { Biodiesel } \\
\text { Content* }\end{array}$ & - & $\% \mathrm{w}$ & $10 \%$ & $\begin{array}{c}\text { FBI } \\
\text { A03-03 }\end{array}$ \\
\hline
\end{tabular}

cetane yang berbeda. Biodiesel B10

Biodiesel Content Analysis will be done when MDGC Equipment ready in laboratory; Sumber: BDF Plant and Laboratory

\subsection{Manfaat Penggunaan Biodiesel Terhadap Lingkungan}

Penggunaan bahan bakar fosil telah menimbulkan berbagai dampak buruk bagi lingkungan. Seperti meningkatnya kadar gas rumah kaca di atmosfer bumi. Jika hal ini dibiarkan secara terus menerus maka pemanasan global adalah konsekuensi yang harus dihadapi oleh seluruh penduduk bumi. Sebagai salah satu sumber energi alternatif, biodiesel dari tanaman jarak pagar ini dapat dikategorikan sebagai sumber energi ramah lingkungan. Karena pembakaran engine yang berbahan bakar biodiesel menghasilkan emisi gas buang, asap dan partikel yang lebih rendah. Angka cetane biodiesel yang lebih tinggi dibandingkan dengan solar membuat emisi gas karbon, nitrogen, dan sulfur lebih rendah. Selain itu, penggunaan biodiesel dari tanaman jarak pagar membuka kemungkinan penanaman kembali lahanlahan kritis yang ada di Indonesia. Saat ini terdapat 13 (tiga belas) juta hektar lahan kering diseluruh Indonesia. Mengingat tanaman jarak pagar merupakan tanaman yang dapat tumbuh di lahan kering dan kurang subur, maka dengan menggunakan biodiesel di Indonesia, lahan-lahan kering tersebut dapat ditanami kembali.

\subsection{Hubungan Antara Daya dan Torsi}

Daya adalah kemampuan melakukan suatu usaha atau kerja dalam setiap satuan waktu tertentu. Sedangkan torsi adalah kemampuan melakukan suatu gerak putar yang besarnya sama dengan perkalian antara gaya dan jaraknya dari sumbu putar. Daya mekanik suatu engine diawali oleh gerak lurus piston dari 
Titik Mati Atas (TMA) ke Titik Mati Bawah (TMB) selama langkah usaha dengan perantara connecting rod dirubah menjadi gerak putar crankpin pada crankshaft.

Di dalam sebuah engine, tentu saja berlaku usaha efektif total piston sama dengan usaha total crankpin.

Jadi $: \mathrm{Wp}=\mathrm{Wcp}$

Atau $: \frac{\pi / 4 \times D^{2} \times \text { BMEP } \times S \times i}{2}$

Karena:

$$
\begin{aligned}
& \mathrm{BHP}=\frac{\pi / 4 \times \mathrm{D}^{2} \times \text { BMEP } \times \mathrm{S} \times \mathrm{i} \times \mathrm{n}}{2 \times 60 \times 550} \\
& \mathrm{BHP}=\frac{\pi / 4 \times \mathrm{D}^{2} \times \mathrm{BMEP} \times \mathrm{S} \times \mathrm{i}}{2} \times \frac{\mathrm{n}}{60 \times 550}
\end{aligned}
$$$$
\mathrm{BHP}=2 \pi \times \mathrm{Tq} \times \frac{\mathrm{n}}{60 \times 550}
$$$$
\mathrm{BHP}=\frac{2 \pi \times \mathrm{Tq} \times \mathrm{n}}{60 \times 550}
$$$$
\mathrm{BHP}=\frac{2 \times 3,1416}{60 \times 550} \times \mathrm{Tq} \times \mathrm{n}
$$$$
=0,0001904 \times \mathrm{Tq} \times \mathrm{n}
$$$$
\mathrm{BHP}=\frac{\text { Tq } \times \mathrm{rpm}}{5252}
$$

Dari rumus yang ada di atas, berlaku untuk torsi dalam satuan ft-lb dan dimana untuk $1 \mathrm{HP}=550 \mathrm{ft}-\mathrm{lb} / \mathrm{dt}$.

Keterangan:

$$
\begin{aligned}
& \operatorname{Torsi}(\mathrm{Tq}) \quad=\text { Torque }(\mathrm{Lb} . \mathrm{ft}) \\
& \text { Daya = Horse power (HP) } \\
& \text { Putaran engine }=\text { Engine Speed }(\mathrm{rpm}) \\
& \mathrm{D}=\text { diameter piston }(\mathrm{m}) \\
& B M E P \quad=\text { Tekanan efektif } \\
& \text { rata-rata }\left(\mathrm{kg} / \mathrm{cm}^{2}\right)
\end{aligned}
$$

\section{Metodologi Penelitian 3.1.Tempat dan Waktu Penelitian}

Tempat penelitian dilakukan di PT. ALTRAK 1978 Balikpapan, sedangkan waktu penelitian dilaksanakan pada bulan Pebruari s/d Desember 2015.

\subsection{Objek Penelitian}

Objek penelitian yaitu menggunakan unit engine Cummins QSK $45 \mathrm{C}$.

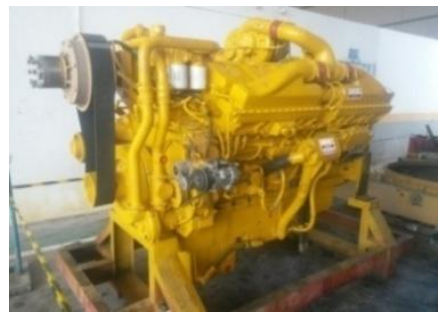

Gambar 1. Engine Diesel Cummins QSK $45 \mathrm{C}$

Spesifikasi engine Cummins QSK $45 \mathrm{C}$ adalah sebagai berikut:

a) Number Of Cylinder : V12

b) Bore and Stroke : $159 \mathrm{~mm}$ (6,26 in) $\mathrm{x} 190 \mathrm{~mm}(7,48 \mathrm{in})$

c) Engine Power $\quad: 1487 \mathrm{HP}$ @ $1900 \mathrm{rpm}$

d) Peak Torque : $5042 \mathrm{Lbft}$ @ $1300 \mathrm{rpm}$

\subsection{Peralatan Yang Digunakan}

Peralatan yang digunakan dalam penelitian ini adalah sebagai berikut:

\subsubsection{Taylor Dynamometer DS4010}

Dinamometer (dynotest) adalah sebuah alat yang digunakan untuk mengukur daya dan torsi yang dihasilkan dari suatu alat yang berputar. Dalam hal ini, alat yang dimaksud adalah engine. Dinamometer memberikan data yang terbaca dalam satuan daya kuda (horse power) serta torsi (torque). 


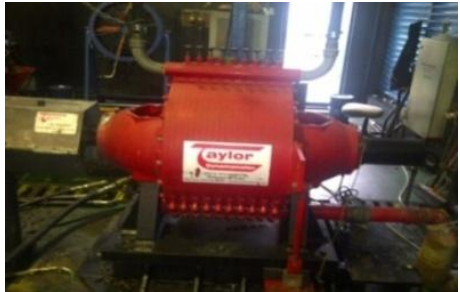

Gambar 2. Taylor Dynamometer DS4010

Adapun spesifikasi dari Taylor Dynamometer DS4010 antara lain:

a) Power: $3.500 \mathrm{HP}(2.611 \mathrm{kw})$

b) Torque: $11.263 \mathrm{Lb} . \mathrm{ft}(15.271 \mathrm{Nm})$

c) Speed : $2.800 \mathrm{rpm}$

d) Water Use: 255 GPM (16,1 L / s)

e) Shipping Weight: $4.620 \mathrm{lbs}(2.097 \mathrm{~kg})$

f) Accessories: Drive Shaft, Adapter Plate Kit, Shaft Guard, Air Stater-Single or Dual Directioanal, Base Kit, Throttle Control, Water Recticulating System, Engine Cart, Closed Loop Cooling System.

\subsubsection{Instrumen Sensor}

Sensor berfungsi untuk mengukur parameter yang ingin diketahui. Sensor yang dipasang meliputi sebagai berikut:

1. Sensor yang dipasang pada engine:
a) Coolant Temperature and Pressure.
b) Oil Temperature and Pressure.
c) Air Inlet Restriction.
d) Intake Manifold Temperature and Pressure.
e) Fuel Rail and Pressure.
f) Fuel Restriction and Temperature.
g) Exhaust Temperature and Restriction.

2. Sensor yang dipasang di ruang dynotest:
a) Coolant Flow Meter : Mengukur debit air pendingin atau coolant yang masuk ke engine.
b) Termukopel : Mengukur suhu ruang dynotest.
c) Plint Fuel Gauge : Mengukur pemakaian atau bahan bakar.

\subsection{Langkah Penelitian}

Melakukan pemasangan engine, langkah yang dilakukan sebagai berikut:

a) Memasang engine pada stand dynotest room.

b) Memasang atau menyambungkan engine dengan dynamometer.

c) Memasang instrumen sensor diantaranya :

1. Coolant temperature and pressure.

2. Oil temperature and pressure.

3. Air inlet restriction.

4. Intake manifold temperature and pressure.

5. Fuel rail pressure.

6. Fuel restriction and temperature.

7. Exhaust temperature and restriction.

d) Menyambungkan peralatan pada engine diantaranya:

1. Air inlet piping.

2. Exhaust piping.

3. Electric harness for command ECM (Electronic Control Module).

4. Battery cables or air supply.

5. Fuel inlet and outlet to engine.

6. Coolant engine inlet and outlet piping.

7. Coolant (LTA) (Low Temperature Aftercooler) inlet and outlet piping.

e) Mengetes kebocoran pada sistem pelumas, pendingin, udara, dan bahan bakar.

f) Mengetes priming pump pada sistem pelumasan.

g) Mengoperasikan engine untuk tes performansi.

h) Melakukan penelitian atau analisa saat engine beroperasi.

i) Mendapatkan data dari hasil pengujian.

j) Mengolah data hasil penelitian.

\subsection{Variabel Penelitian}

Variabel dalam penelitian ini antara lain: 
a. Variabel Bebas

- putaran engine (rpm).

b. Variabel Terikat

- torsi engine (lb-ft)

- daya engine (HP)

c. Variabel Kontrol

- temperatur ruang uji Dynotest 28-30 ${ }^{\circ} \mathrm{C}$.

\section{Hasil Dan Pembahasan}

\subsection{Hasil Pengukuran Dengan Dynotest}

Bedasarkan hasil pengujian diperoleh data-data nilai daya pada putaran engine 1000, 1200, 1300, 1400, 1500, 1700, 1800, dan 1900 rpm sebagai berikut:

Tabel 3. Data Hasil Pengukuran Daya Antara B10 dan Solar

\begin{tabular}{|c|c|c|c|}
\hline No & $\begin{array}{c}\text { Putaran } \\
\text { Engine } \\
\text { (rpm) }\end{array}$ & $\begin{array}{c}\text { Daya Engine } \\
\text { B10 } \\
\text { (HP) }\end{array}$ & $\begin{array}{c}\text { Daya Engine } \\
\text { Solar } \\
\text { (HP) }\end{array}$ \\
\hline 1. & 1006 & 803.126 & 828.144 \\
\hline 2. & 1200 & 1105.809 & 1118.345 \\
\hline 3. & 1301 & 1216.465 & 1248.752 \\
\hline 4. & 1402 & 1304.220 & 1344.523 \\
\hline 5. & 1500 & 1382.343 & 1402.287 \\
\hline 6. & 1702 & 1419.743 & 1433.831 \\
\hline 7. & 1801 & 1408.898 & 1457.214 \\
\hline 8. & 1901 & 1432.280 & 1468.763 \\
\hline
\end{tabular}

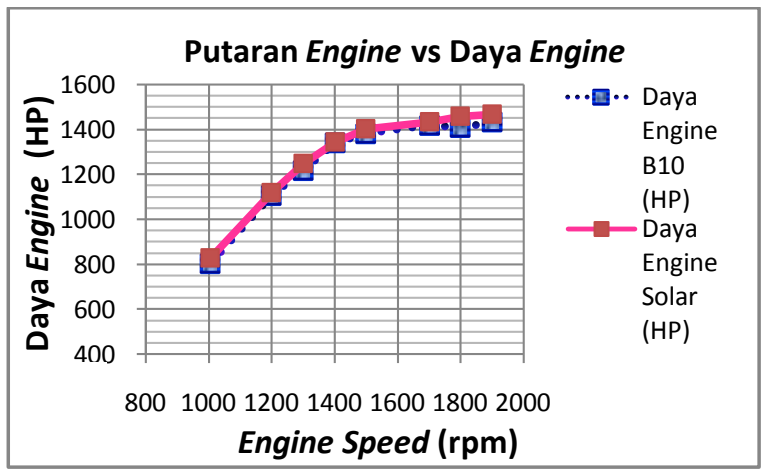

Gambar 3. Grafik Perbandingan Antara Putaran Engine Terhadap Daya Engine Pada Bahan Bakar B10 dan Solar

Gambar 3 di atas merupakan grafik yang menunjukkan daya engine maksimum dari masing-masing engine tercapai pada putaran $1901 \mathrm{rpm}$ yaitu sebsear 1432 HP untuk B10 dan 1468 HP untuk solar. Sedangkan untuk data hasil torsi engine dilakukan pada putaran engine 1000, 1200, 1300, 1400, 1500, 1700, 1800, dan 1900 rpm. Adapun data yang diperoleh adalah sebagai berikut:

Tabel 4. Data Hasil Pengukuran Torsi Antara B10 dan Solar

\begin{tabular}{|c|c|c|c|}
\hline No & $\begin{array}{c}\text { Putaran } \\
\text { Engine } \\
(\mathrm{Rpm})\end{array}$ & $\begin{array}{c}\text { Torsi Engine } \\
\text { B10 } \\
(\mathrm{lb}-\mathrm{ft})\end{array}$ & $\begin{array}{c}\text { Torsi Engine } \\
\text { Solar } \\
(\mathrm{lb}-\mathrm{ft})\end{array}$ \\
\hline 1. & 1006 & 4233.983 & 4360.342 \\
\hline 2. & 1200 & 4789.655 & 4885.785 \\
\hline 3. & 1301 & 4929.300 & 5016.189 \\
\hline 4. & 1402 & 4823.721 & 5009.532 \\
\hline 5. & 1500 & 4808.250 & 4937.865 \\
\hline 6. & 1702 & 4450.430 & 4529.453 \\
\hline 7. & 1801 & 4275.296 & 4326.214 \\
\hline 8. & 1901 & 4016.400 & 4109.335 \\
\hline
\end{tabular}

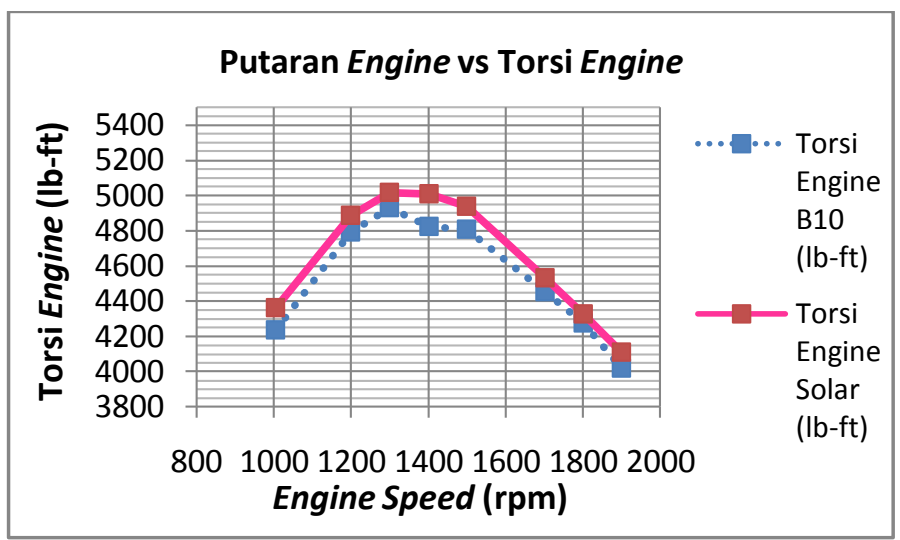

Gambar 4. Grafik perbandingan Antara Putaran Engine Terhadap Torsi Engine Pada Bahan Bakar B10 dan Solar

Gambar 4 merupakan grafik yang menunjukkan nilai torsi engine maksimum dari masing-masing engine tercapai pada putaran $1301 \mathrm{rpm}$ yaitu sebsear $4929 \mathrm{lb}-\mathrm{ft}$ untuk B10 dan 5016 lb-ft untuk Solar.

\subsection{Pembahasan}

Dari hasil pengujian dynotest yang sudah dilakukan merupakan hubungan putaran engine terhadap nilai daya dan torsi yang menggunakan bahan bakar B10 dan solar. 


\section{a. Daya / Power}

Pada gambar 3 di atas menunjukkan grafik nilai daya tertinggi yaitu pada putaran engine $1900 \mathrm{rpm}$. Penggunaan bahan bakar biodiesel B10 dengan nilai daya 1432,28 HP, sedangkan solar sebesar 1468,763 HP, maka persentasenya adalah sebesar:

$$
\frac{1432,28}{1468,763} \times 100 \%=97,51 \%
$$

Sehingga dapat diketahui penggunaan biodiesel B10 mengalami penurunan nilai daya engine sebesar 2,49\%.

\section{b. Torsi / Torque}

Gambar 4 di atas menunjukkan nilai torsi tertinggi yaitu pada putaran engine $1300 \mathrm{rpm}$. Penggunaan bahan bakar biodiesel B10 dengan nilai torsi 4929,300 lb-ft, sedangkan solar sebesar 5016,189 lb-ft, maka persentasenya adalah sebesar:

$\frac{4929,300}{5016,189} \times 100 \%=98,27 \%$

Sehingga dapat juga diketahui penggunaan biodiesel B10 mengalami penurunan nilai torsi engine sebesar $1,73 \%$.

\section{Kesimpulan}

Bedasarkan hasil dan pembahasan, maka dapat diambil kesimpulan sebagai berikut :

1. Pergantian bahan bakar dari solar ke biodiesel ini sangat baik karena dapat mengurangi penggunaan bahan bakar fosil yang termasuk tidak dapat diperbaharui dan keberadaannya saat ini mulai menipis, sedangkan untuk biodiesel sendiri adalah jenis bahan bakar yang dapat diperbaharui.

2. Pada pengujian performansi dengan alat uji dynotest, pada penggunaan bahan bakar biodieel B10 didapatkan nilai daya maksimal sebesar 1432,28 HP pada putaran engine $1901 \mathrm{rpm}$ dan nilai torsi maksimal sebesar 4929,3 lb-ft pada putaran engine $1301 \mathrm{rpm}$.
4. Persentase daya engine maksimal dengan menggunakan bahan bakar biodiesel B10 dibandingkan dengan solar pada putaran engine yang sama hanya sebesar $97,51 \%$ sedangkan untuk torsi sebesar $98,27 \%$.

\section{Ucapan Terima Kasih}

Terima kasih ditujukan kepada PT. ALTRAK 1978 Balikpapan yang telah memberikan tempat dan fasilitas dalam penelitian ini.

\section{Daftar Pustaka}

A.R. Holowenko dan Cenddy Prapto. 1995, Dinamika Permesinan, Erlangga, Jakarta.

Altrak 1978 PT., 2011, Basic Mechanic Course, Training Module-Part 1, PT Altrak 1978, Balikpapan.

Altrak 1978 PT., 2011, Basic Mechanic Course. Training Module-Part 2, PT Altrak 1978, Balikpapan.

Altrak 1978 PT., 2010, Operation And Maintenance Manual Cummins QSK 45 C, PT Altrak 1978, Balikpapan.

Arismunandar, W, 2002, Penggerak Mula Motor Bakar Torak, Edisi kelima, Institut Teknologi Bandung (ITB), Bandung.

Arismunandar, W dan Kuichi Tsuda, 2004, Motor Diesel Putaran Tinggi, PT. Pradnya Paramita, Jakarta.

Farin W., 2011, Penggunaan Bahan Bakar Nabati Biosolar Dari Tanaman Jarak Pengganti Bahan Bakar Fosil Solar, http://farinlutvy.blogspot.co.id/2011/11/pe nggunaan-bahan-bakar-nabatibiosolar.html, Diakses tanggal 10 April 2015. 
Intan R.P. 2010, Bahan Bakar, www.nayhndy.wordpress.com. Diakses tanggal 15 April 2015

Pratiwi Praningrum. 2008, Biodiesel Dari Tanaman Jarak Sebagai Energi Alternatif Pengganti Solar. www.gbioscience05.wordpress.com.

Diakses tanggal 12 Mei 2015
Wikipedia. 2014, Pengertian Bahan Bakar, www.wikipedia.org. Diakses tanggal 28 Mei 2015

Willard W. Pulkrabek, 2000, Engineering Fundamentals of the Internal combustion Engine (second edition), Prentice Hall, New Jersey. 